'llu. Revista de Ciencias de las Religiones

ISSN: 1135-4712

http://dx.doi.org/10.5209/ILUR.57419

\title{
Taiping Jing 太平經: Fuente para la institucionalización del taoísmo religioso
}

\author{
Alberto Poza Poyatos ${ }^{1}$
}

Recibido: 1 de junio de 2016 / Aceptado: 14 de enero de 2017

Resumen. La decadencia del gobierno Han en los primeros siglos de nuestra era deriva en una sociedad receptiva a los mensajes salvíficos que propicia la aparición de movimientos milenaristas. Estas organizaciones, con unos valores fundamentados en la cosmología taoísta, desarrollan un nuevo discurso en torno a la moral y la responsabilidad social, instauran una nueva fuente de autoridad personificada en los maestros y en definitiva; plantean por primera vez un modelo alternativo y crítico con la ortodoxia confuciana vigente. En este trabajo se analiza el papel del Taiping Jing «Escritos sobre la Gran Paz» como nueva fuente de autoridad textual para estos procesos y su importancia en la cohesión del movimiento taoísta y posterior institucionalización de lo que algunos autores denominan taoísmo religioso.

Palabras clave: Taiping Jing; Gran Paz; Han; taoísmo.

\section{[en] Taiping Jing 太平經: A Source for the Institutionalization of Religious Daoism}

\begin{abstract}
During the first centuries of our age, the decadence of the Han government contributed to a society receptive to salvific ideas and in turn, favored the advent of millenialist movements. These organizations, with its values well rotted in Daoist cosmology, would develop a new discourse around the ideas of moral and social responsibility, would install a personified source of authority in the figure of the master and would propose a critical alternative to the prevailing Confucian orthodoxy. In this paper I analyze the role of the Taiping Jing «The Scripture on Great Peace» as the textual source of authority for the aforementioned processes and its importance to unite and institutionalize the Daoist movement to allow it become what some authors would label as «religious Daoism».
\end{abstract}

Keywords: Taiping Jing; Great Peace; Han; Daoism.

Sumario. 1. Introducción. 1.1. Historia textual. 1.2. Contexto histórico 2. Taiping Jing: Fuente para la institucionalización del taoísmo religioso 3. Conclusión. 4. Bibliografía.

Cómo citar: Poza Poyatos, A. (2017), Taiping Jing 太平經: Fuente para la institucionalización del taoísmo religioso, en 'Ilu. Revista de Ciencias de las Religiones 22, 323-341.

\footnotetext{
1 Universidad Autónoma de Madrid (España) / School of Oriental and African Studies (SOAS) University of London (Reino Unido).

E-mail: alb.poza90@gmail.com
} 


\section{Introducción}

Durante los dos primeros siglos de nuestra era, en un contexto de revueltas propiciado por la decadencia de la dinastía Han (206 a. C.-220 d. C.), comenzaron a extenderse algunos movimientos milenaristas que señalaban el fin de un ciclo y difundían entre las gentes su mensaje salvífico utilizando y redefiniendo el ideario chino, su cosmología y sus leyes morales. En esta época en la que los textos servían de instrumento legitimador del sistema imperial, surgió una nueva fuente de autoridad escrita que desafiaría a la ortodoxia: la revelación ${ }^{2}$. Con esta nueva autoridad que confería la revelación, el Taiping Jing 太 平經 ${ }^{3}$ 《Escritos sobre la Gran Paz» trajo esperanza a las gentes mientras el sistema Han colapsaba.

En este artículo se van a analizar los argumentos sobre los que se legitimó la aparición de un texto de estas características en el contexto Han y su papel en la posterior institucionalización del movimiento taoísta, en cuya filosofía parece haber basado su mensaje. Para ello voy a utilizar como fuentes primarias la versión en lengua china de 1960 Taiping jing he xiao 太平經合校 de Wang Ming Bian 王明编 y, ya que he sido yo mismo quien ha redactado las traducciones al español que aparecen en este artículo, he considerado oportuno añadir también a pie de página referencias a la primera traducción oficial completa a una lengua occidental de los «Escritos sobre la Gran Paz», publicada en 2007 por Barbara Hendrischke sobre la edición de Wang Ming de 1979. El objetivo de añadir estas referencias a la traducción inglesa es que el lector pueda contrastar ambas versiones y superar las carencias que pueda tener mi interpretación.

La versión del Taiping Jing 太平經 《Escritos sobre la Gran Paz» (de aquí en adelante: TPJ) que conservamos pertenece a la compilación Zhengtong daozang 正 統道藏 editada durante el periodo Zhèngtǒng 正統 (1435-1449) de los Ming (13681644 d. C.) y está dividida en 57 capítulos (juăn 卷) y subdividida en 129 secciones $^{4}$.

Consciente de la imprecisión del término «taoísmo» y de la dificultad de acotarlo, en este trabajo se utiliza este concepto para referirse tanto a la corriente de pensamiento derivada de la filosofía de Lao Tse 老子 y Zhuang Zi 莊子 ${ }^{5}$ (murió en torno al 286 a. C. ), como a las prácticas populares que, pese a no tener un vínculo directo con las fuentes escritas de este taoísmo filosófico, tienen la inmortalidad como objetivo de su práctica.

Actualmente, el TPJ constituye el texto central de la sección Taiping 太平 y se encuentra contenido en la categoría del canon taoísta (dàozàng 道藏) denominada los Cuatro Suplementos (Sifu 四輔). Por canon taoísta nos referimos a la colección de escritos relativos al taoísmo que se encuentra dividida en dos bloques: las Tres Cavernas (Sandong 三洞), con documentos reunidos en torno al siglo $\mathrm{V}$ d. C. como únicos

2 El primero en concebir el texto taoísta como un producto de las élites al margen de la tradición central y con un objetivo político será Marcel Granet (1925).

3 El autor de este artículo utiliza el sistema de transcripción Hanyu Pinyin a lo largo de todo el texto, manteniendo los tonos en aquellos términos que no se refieren al nombre propio de una obra u autor por considerar que forman parte integral de la palabra y pueden ser de ayuda en la investigación de ciertos conceptos en su idioma original. De este modo, Taiping Jing hace referencia al título de la obra, mientras que Tàipíng sería la transcripción fonética de 太平, que se ha decidido traducir como «Gran Paz». De igual manera, jīng conservará el tono cuando se refiera al término 經, que se ha traducido como «clásicos».

4 Ofuchi 1979, 253-267.

5 Con el objetivo de fomentar la estandarización de ciertos términos que ya se encuentran en uso en castellano, el autor ha decidido utilizar las traducciones ya existentes de estos nombres propios en lugar de proveer una alternativa o su transcripción fonética en Hanyu Pinyin. 
componentes del canon, y por otra parte; los Cuatro Suplementos, probablemente añadidos en el siglo VI d. C. como complemento a las Tres Cavernas. La misma creación de este canon en torno a los siglos IV y V d. C. podría considerarse el resultado de la sistematización de las creencias y las prácticas populares que estaba teniendo lugar durante la época Han. Hasta los primeros siglos de esta dinastía, estas creencias y prácticas populares consistían principalmente en ritos inspirados en una visión cosmológica basada en la interacción de diferentes agentes, en la representación antropomórfica de los espíritus, y en los rituales y sacrificios que servían como vías de comunicación entre el reino de los vivos y su gobierno homólogo en el reino de los muertos. Pese a compartir una visión cosmológica común fundamentada en lo que podríamos llamar filosofía taoísta ${ }^{6}$, parece que el sentimiento de cohesión necesario entre estos practicantes para institucionalizarse y crear un canon no se debió a una repentina iniciativa interna en favor de la unión de las distintas escuelas existentes, sino a la acción de factores externos como la aparición del budismo, de carácter más cohesivo, en el que los fieles y los monjes se organizan en torno a ciertos sistemas jerárquicos y existen unas escrituras de carácter canónico ${ }^{7}$. Aunque no existe el taoísmo como tal entendido como una comunidad consciente de un mismo objetivo e intereses hasta la compilación del canon, la llegada de un movimiento religioso organizado desde el extranjero habría comenzado a generar entre los practicantes de los ritos taoístas de las distintas regiones chinas una idea de pertenencia y de grupo que sirvió de impulso para su cohesión ${ }^{8}$. De hecho, es palpable la influencia del concepto jerárquico budista de los Tres Vehículos (Sancheng 三乘) a la hora de clasificar los textos taoístas en Tres Cavernas. Por otra parte, la posterior incorporación de los Cuatro Suplementos parece responder a un cambio hacia una ideología más inclusiva en la identidad taoísta que buscaba aglutinar todas las prácticas populares fundadas en una cosmología similar y que se encontraban diseminadas por toda la geografía china.

La mayor parte de los académicos coinciden en señalar el siglo II d. C. como el momento histórico en el que los practicantes de estos ritos populares con características taoístas se agrupan en torno a textos fuera de la ortodoxia y del canon de los clásicos confucianos. Estos textos, a menudo deificados o con carácter revelado, sentaron las bases para la aparición del taoísmo religioso organizado o «Iglesia Taoísta», como lo denomina Demiéville ${ }^{9}$. Hasta este momento, en el que los conceptos del TPJ se popularizaron, los practicantes de los ritos taoístas formaban parte de un grupo heterogéneo al margen del aparato gubernamental -cuya ortodoxia eran los clásicos confucianos- y sin un corpus textual reconocido pero, con el declive de la dinastía y la consecuente pérdida de amparo imperial para la clase confuciana, la identidad de grupo taoísta se empezó a vincular con los mensajes mesiánicos revelados, la divini-

6 Filosofía taoísta no se refiere a un grupo en términos sociológicos. Aquí se emplea como un concepto que engloba a distintos autores que, a lo largo de la historia, han producido una obra filosófica en común (Sivin 1978, 305).

7 Barret (2010), ofrece una explicación de esta cohesión que imita un diseño burocrático desde el punto de vista de los restos materiales en línea con la interpretación de Anna Seidel (1989), para quien también es palpable la urgente necesidad de estos movimientos por organizarse en torno a elementos comunes y en relación a los poderes institucionalizados.

$8 \quad$ Sivin 1978, 303-330.

9 Demiéville 1986, 808-820.

Es interesante apuntar que la creciente concepción de estos textos como revelaciones implica también un cambio en su uso. No se tratan ya de escrituras filosóficas sino que su lectura se vuelve inseparable de la práctica religiosa y el rito y por tanto, empiezan a jugar un papel fundamental en la legitimación del grupo y en la transmisión del mensaje religioso (Sivin 1978, 306). 
zación de textos como el Lao Tse y la figura del maestro $\left(\operatorname{sh} \overline{1}\right.$ 師 $^{10}$. Este fenómeno, mediante el cual se concede a un texto carácter divino y por tanto legitimador, se vale de la misma lógica por la que un objeto entregado por una de las familias gobernantes (băo寶) otorgaba poder al portador. De este modo, una escritura taoísta obtenida a través de una revelación tenía el mismo valor que estos objetos ya mencionados; al margen del valor del escrito, el objeto material en sí, al haber sido entregado por una autoridad superior, confería legitimidad al portador ${ }^{11}$.

Los conceptos centrales de esta nueva identidad taoísta y sobre los que también se empezaron a organizar los primeros movimientos milenaristas alternativos al modelo confuciano se encuentran en el TPJ y son el de la Gran Paz (Tàipíng 太平), que da nombre al texto y que remonta sus orígenes a diversos textos pre-Han del periodo de los Reinos Combatientes (475-221 a. C.), y el del Reino de la Gran Paz, un momento histórico idealizado en el que el Tao (dào 道) - el orden fundamental e innombrable del universo- marcaba el camino de la vida sin que los hombres supusieran un bloqueo para el $q i$ 氣 - la energía vital cuyo bloqueo se considera la base de cualquier trastorno- por lo que el gobierno de los hombres era armonioso. Esta idea de una sociedad utópica inspirada en el pasado legendario de China se popularizó en tiempos de los Han y con ella el modelo cosmológico en la que se basaba ${ }^{12}$. En consecuencia, los escritos como el TPJ, que contenían el testimonio y las instrucciones para alcanzar esta sociedad armónica que permitiría que el Tao se revelara y actuase, se revalorizaron.

Este valor que se concedió a los escritos no era nuevo en esta época, ya desde finales del periodo de los Reinos Combatientes la importancia de los clásicos (jīng 經) como referente de autoridad había sido central en el gobierno del estado y en el ámbito intelectual. Las continuas referencias a estos clásicos fueron elevando su categoría de narración, compendio o testimonio de otra época a la de fuentes de autoridad política y moral contemporáneas, convirtiéndolos en muchos casos en modelos de buen gobierno y fuente primaria para el conocimiento de los fundamentos sociales, políticos y morales que ayudaban a dar forma y cohesión a la sociedad, como ocurre en el caso del $T P J^{13}$. Compilados tradicionalmente por la clase educada confuciana (rú 儒) y patrocinados por el estado, estos clásicos habían sido las fuentes sobre las que los gobernantes habían legitimado sus actos desde que en el año 124 a. C. el emperador Wu de los Han (漢武帝) (156-87 a. C.) creara la Academia Imperial (tàixué 太學) ${ }^{14}$ y otorgara el monopolio cultural a los confucianos y a sus cinco clásicos ( «El libro de las Odas»Shi 詩, «Los Documentos》Shu 書, «Los Ritos》Liji 禮記, «Los Cambios》Yi 易 y los «Anales de Primavera y Otoño» Chunqiu 春秋). Otra característica importante del significado del carácter jīng 經 es que no sólo hace referencia a la amplitud de los saberes interconectados que abarca, sino también a la perdurabilidad y constancia de éstos a lo largo del tiempo, otorgándoles un valor que va más allá de lo temporal ${ }^{15}$.

10 Demiéville 1986, 808-820.

Seidel 1989-1990, 250.

12 Anna Seidel (Dic. 1984, 169, 170) recoge varias citas que prueban la popularización de esta nostalgia por un pasado utópico y su relación con el mensaje mesiánico taoísta.

Es curioso también que Rolf Stein (1963) relacione las ideas referidas a este gobierno utópico con las que circulaban en torno al concepto Dàqín 大秦, utilizado para referirse al Imperio Romano. De acuerdo con el trabajo de Samuel N.C. Lieu (2013), el término Dàqín también comenzó a usarse en la época Han.

Bokenkamp 1997, 20s.

Nylan 2001, 35.

Lewis 1999, 297-302. 
En el apartado de contexto histórico se aborda uno de los motivos clave para la popularización de los contenidos del TPJ en la época Han: la percepción generalizada de caos social y político. Son muchos los autores que consideran el contexto histórico de los Han un factor determinante para el éxito del mensaje del TPJ, ya que se trataba de un momento en el que las luchas internas de poder entre eunucos y letrados confucianos debilitaban la capacidad de la corte de ejercer el gobierno y los problemas en el campo, fruto de las numerosas catástrofes naturales, lastraban la economía. Cada vez más, surgían hombres influyentes que declinaban servir al estado y encontraban mayor reconocimiento a su valía sirviendo como líderes locales ${ }^{16}$. Estos factores llevaron a que durante los dos últimos siglos de la era Han, la corte fuera progresivamente perdiendo su capacidad para generar riqueza, cooptar a los líderes de los distintos estados y, en definitiva, de mantener el poder centralizado en torno al emperador. Este caos generalizado derivó en una sociedad receptiva a los contenidos salvíficos del TPJ, que se extendieron con cierta rapidez entre las distintas clases sociales influenciando el pensamiento Han y favoreciendo la aparición de movimientos milenaristas que exigían la rearmonización del estado según un modelo diferente al establecido: el modelo cosmológico taoísta propuesto en los escritos de la Gran Paz. Estas organizaciones, al constituirse como fuente de autoridad al margen de la corte, supusieron una alternativa enfrentada al poder central y a la burocracia administrativa del gobierno, estrechamente ligada al confucianismo. Los Turbantes Amarillos (Huángjīn 黄 巾) (184-205 d. C.) en el este de China y los Cinco Celemines de Arroz (Wǔdǒumǐdào 五斗米道) (206 a. C.-220 d. C.) en el oeste, en la región de Sichuan, proyectaron sistemas de organización jerárquicos construidos en torno a la utopía del Reino de la Gran Paz que sentarían las bases del futuro taoísmo religioso diferenciándolo de lo confuciano e influirían en la aparición del sentimiento de cohesión necesario para promover la compilación del canon taoísta ${ }^{17}$.

Pese a que parece evidente el valor que el TPJ puede tener en el estudio del pensamiento Han y especialmente en el de las rebeliones de los Turbantes Amarillos, existen discrepancias acerca de su validez como fuente fiable ya que, como ya he comentado, la versión que conservamos actualmente fue editada durante el periodo Zhèngtǒng (1435-1449 d. C.) de los Ming y desconocemos la fidelidad de nuestra versión al texto que podría circular en la dinastía Han y las transformaciones que habría podido sufrir desde su inclusión al canon en la dinastía Tang (618-907 d. C.) Por este motivo, en la primera parte de este trabajo se analiza su historia textual, buscando la consistencia histórica de los conceptos que hoy nos muestra el TPJ.

\subsection{Historia textual}

Las primeras pruebas de la existencia del TPJ son cinco citas recogidas en el Hou Hanshu 後漢書 (siglo V d. C.) referidas a la dinastía Han. En estas citas se cuenta como Gan Zhongke 甘忠可 (murió en torno al 22 a. C.) y sus discípulos, entre los que destaca Xia Helian 夏賀良, se muestran conocedores del TPJ, del pronóstico del fin de la dinastía y de la solución que el texto propone para restaurar el Mandato del

\footnotetext{
16 La historia del viaje de Gan Ji 千吉 con el texto revelado también sigue esta narrativa en la que una situación de caos hace imprescindible la llegada de un salvador. En la cita recogida por Mansvelt Beck $(1980,177)$ queda también patente la predisposición de las gentes a abrazar las ideas mesiánicas.

17 Demiéville 1986, 808-820.
} 
Cielo (Tiānmìng 天命). Cuenta también cómo la inclusión de este escrito en el canon es rechazada en un primer momento por Liu Xiang 劉向 (77-6 a. C.) y después por su hijo Liu Xin 劉歆 (murió en el 23 d. C.), ambos bibliotecarios en la corte. La ortodoxia confuciana de este momento encuentra el mensaje del $T P J$ contrario a los clásicos y los discípulos de Gan Zhongke son declarados culpables de adhesión a doctrina herética y de tratar de confundir al gobierno con sus predicciones y consejos. La siguiente aparición del TPJ en el Hou Hanshu se encuentra en un pasaje que narra cómo Gong Chong 宫崇 primero y veinte años después, en el 166, Xiang Kai 裏楷, viajan desde Langya 琅㑚, en el actual Shandong 山束, para entregar en la corte dos memoriales. En uno de estos memoriales, Xiang Kai, preocupado por el futuro de la dinastía ante la falta de herederos del emperador Huan 漢桓帝 (132-168 d. C.), recomienda un texto revelado, y las prácticas que en él se encuentran, al maestro Gan Ji 千吉 (murió en el 200 d. C.) para solucionar el problema de la descendencia y revitalizar el estado. Sobre estos dos memoriales, el historiógrafo Fan Ye 范眸 (398446 d. C.) añade una nota bibliográfica en la que, lo que sería el TPJ, aparece titulado Taiping Qingling Shu 太平清領書 y se le vincula por primera vez con Zhang Jue 張 角 (murió en el 184 d. C.), ideólogo del movimiento de los Turbantes Amarillos ${ }^{18}$.

La posible influencia de la versión del TPJ que, según Fan Ye, Zhang Jue conocía, ha generado mucha discusión entre los estudiosos del texto en el siglo XX. No obstante, parece mayoritaria la opinión de que, al no haberse encontrado pruebas textuales contemporáneas a Zhang Jue relacionando su pensamiento con los conceptos del Taiping Qingling Shu y teniendo en cuenta que el texto es varios siglos posterior al levantamiento de los turbantes amarillos, es más probable que fuera el pensamiento de Zhang Jue el que influenciara al texto en su transformación histórica y no al revés ${ }^{19}$.

Cien años antes de que Fan Ye redactara su obra, Yu xi 虞喜 (307-343 d. C.), en su obra historiográfica Zhilin 志林, ya se mostraba conocedor de la existencia de un TPJ. En citas del Zhilin recogidas en los comentarios de Pei Songzhi 裴松之 (372-451 d. C.) al Registro de los Tres Reinos (Sanguo Zhi 三國志) se encuentra una descripción similar a la que hace Fan Ye del TPJ, lo que ha dado a pensar que ambos se basaron en la misma fuente, aunque probablemente ninguno tuviera nunca acceso a un TPJ.

Es interesante apuntar que, a diferencia de Gong Chong, que era un maestro taoísta, Xiang Kai pertenecía a la burocracia más cercana al gobierno, de lo que Barbara Hendrischke deduce que en estos veinte años de diferencia que hay entre la vida de uno y otro, el TPJ ganó en popularidad hasta el punto de que comenzó a circular entre la clase dirigente ${ }^{20}$.

En todas las referencias históricas al TPJ existen algunos elementos comunes: el texto se presenta como compendio de los remedios a la decadencia de la dinastía, para regenerar el estado y dar herederos al emperador. Estas fuentes explican tam-

18 Mansvelt Beck 1980.

19 Esta posición con relación a la historia textual del TPJ es compartida por un gran número de expertos, de entre los que Mansvelt (1980) y Espesset (2008) destacan a Yoshioka Yoshitoyo [«On a Tunhuang MS of the Taiping Jing», 1961] y Fukui Kojun [«An Inquiry into the TPJ», 1936, 1937]. Estos autores basan su opinión en la imposibilidad histórica de que el pensamiento de Zhang Jue fuese influenciado por el texto. De acuerdo a sus argumentos, la posibilidad más razonable parece ser que ocurriese al contrario. Para un desglose en mayor profundidad de esta discusión ver: Mansvelt Beck 1980, 150, 151 y Espesset 2008.

20 Hendrischke 2001, 32. 
bién cómo el caos social, político y económico era resultado de la falta de fe del anterior emperador en los remedios contenidos en el TPJ y de la necesidad de adoptarlos cuanto antes para restaurar el Mandato del Cielo. Aunque no podemos asegurar que todas las citas al TPJ se refieran al mismo texto, parece probable que durante la era de los Han circulaban documentos que compartían los conceptos revelados a Gan Ji de los que se habla en el TPJ que conservamos.

Ge Hong 葛洪 (283-343 d. C.) también se refiere en sus «Biografías de los Inmortales» (Shenxian Zhuan 神仙傳) (300 d. C.) a un texto en seda (sùshū 素書) que Bo He 帛和-un vendedor de remedios medicinales- entregó a Gan Ji para que curase su enfermedad y difundiera sus enseñanzas sanando a los enfermos. No obstante, Campany (2002) asegura que la vinculación de este sùsh ū que aparece tanto en las 《Biografias de Inmortales» como en el Baopuzi Neipian 抱朴子 內篇 (cap.19 n ${ }^{\circ} 18$ ) con el TPJ es una presunción posterior y que Gan Ji, quien aparece en numerosas fuentes desde el siglo VI hasta el siglo XIV, pudo haber sido contemporáneo de $\mathrm{Ge}$ Hong y desconocer la existencia del $T P J^{21}$.

En el 550 encontramos otra referencia al TPJ en el prefacio de las «180 Instrucciones del Maestro Lao» (Laojun Shuo Yibai Bashi Jie 老君說一百八十戒), relacionado con las enseñanzas de Lao Tse ${ }^{22}$. Aparece una vez más en la obra de Ma Shu 馬樞 (murió en el 581 d. C.) denominada «Biografías de Taoístas» (Daoxue Zhuan 道學傳) y en la obra 《Importancia General del Portal de los Misterios» (Xuanmen Dayi 玄門大義) de los Sui (589-618 d. C.)

El manuscrito de la primera mitad del siglo VII encontrado en Dunhuang, el Taiping Bu Juan Di'Er 太平部卷第二, y en el que se enumeran los contenidos del TPJ, confirma, por una parte, la existencia de una única versión del texto que hemos recibido como TPJy, por otra, que esta es igual a las versiones que circulaban en el siglo VII.

A partir de este momento, las palabras Tàipíng jīng aparecen en numerosas fuentes, sobre todo desde el periodo Tang en adelante. Para este entonces, el texto ya formaba parte del canon taoísta y sus modificaciones hasta la edición de 1445 de los Ming que conocemos responden al proceso transformador de las diversas reediciones a las que se ha visto sometido el canon a lo largo de los siglos ${ }^{23}$.

A la luz de la historia textual del $T P J$ podemos concluir que es arriesgado afirmar la existencia de un documento unitario TPJ como lo conocemos hoy en día más allá del siglo VII pero que sin embargo, si existe cierta consistencia en el mensaje desde el siglo I a. C. por lo que, pese a las modificaciones de cada edición, parece probada la existencia y popularidad del concepto de Gran Paz Tàipíng a lo largo de la historia de China y por lo tanto, parece factible que sobre estos conceptos que hoy recoge el $T P J$ se fundamentara la cohesión de las distintas escuelas con bases taoístas en el siglo II d. C. y el impulso para la compilación de un canon.

\subsection{Contexto histórico}

El contexto histórico de la dinastía Han fue uno de los factores principales que aseguraron el éxito y la enorme difusión de la teoría milenarista de la Gran Paz a todos los niveles sociales.

\footnotetext{
Campany 2002, 302, 491s.

Mansvelt Beck 1980, 162.

Espesset 2008.
} 
El final de la dinastía Han se caracterizó por la fragmentación del poder y la decadencia en la corte, dividida en luchas faccionarias entre los eunucos y los letrados. Ante la inexistencia de un gobierno central eficaz, los terratenientes locales empezaron a reunir el poder suficiente para desafiar las decisiones imperiales. Estos poderes locales luchaban por ganar competencias al gobierno central y trataban de canalizar el descontento de la sociedad, que sufría las consecuencias de un sistema económico en crisis y de una consecución de malas cosechas y desastres naturales.

En este contexto se gestaron las rebeliones que ayudarían a poner fin a la dinastía. Un grupo de alquimistas, herboristas y curanderos taoístas presentaron esta desafortunada situación general como el presagio del fin del ciclo Han legitimando así lo que a finales de la dinastía Han los revolucionarios llamarían el Paraíso Amarillo (Huáng Tiān 黄天).

Esta idea se popularizó especialmente en el este de China, la zona más castigada por la crisis, donde Zhang Jue y sus dos hermanos dirigieron el descontento social hacia lo que se conoce como la Rebelión de los Turbantes Amarillos, apodada así haciendo referencia al color de los pañuelos que llevaban sus militantes en la cabeza durante los levantamientos ${ }^{24}$.

Los Turbantes Amarillos y los Maestros Celestiales de la escuela de los Cinco Celemines de Arroz compartían la característica de ser movimientos milenaristas fundamentados en la cosmología taoísta y contrarios a la dinastía Han. Promovieron levantamientos en contra del emperador y, tanto sus enseñanzas como la jerarquía que desarrollaron dentro de sus movimientos sentaron las bases para la progresiva institucionalización del movimiento taoísta.

Es importante destacar que, en el transcurso de las sublevaciones, estos movimientos impusieron un gobierno al margen de las unidades territoriales dictadas por el gobierno central, con unidades territoriales y cargos militares y políticos propios. Dos figuras importantes dentro de estas nuevas jerarquías y a su vez, ejemplo de cómo la revelación revierte en un poder político es primeramente la de los libadores (jìjiǔ 祭酒); funcionarios taoístas al mando de cada distrito y encargados de instruir en los contenidos del Dao De Jing 道德經, dirigir oraciones y llevar a cabo curaciones por medio de la fe. La otra figura relevante fue la de los médiums (yāowū 妖 巫 o wūrén 巫人), a quienes posteriormente también se denominaría ladrones de grano (mǐzéi 米賊), médiums del grano (mǐwū 米巫) o gentes del grano (mǐmín 米 民); y a quienes se atribuye el liderazgo del levantamiento de los Cinco Celemines de Arroz ${ }^{25}$.

En definitiva, fue en este momento histórico cuando se institucionalizó la aplicación de una doctrina religiosa politizada y militarizada basada en los textos -a los cuales se había conferido carácter de revelación- y en sus comentarios, que se habían alejado ya del pensamiento y los valores promulgados en el Lao Tse.

Finalmente, y gracias a la inacción del emperador, que había desoído las informaciones que le anticipaban la sublevación, el 4 de abril del 184 estalla la Rebelión de los Turbantes Amarillos que, pese a no conseguir su objetivo de derrocar al emperador, sirve de ejemplo a una serie de levantamientos posteriores que debilitarán a la corte en favor de los terratenientes locales.

Demiéville 1986, 808-820.

Espesset 2009, 1065-1072. 
Pese a la ejecución de los hermanos Zhang y un gran número de sus seguidores, la administración religiosa de los libadores siguió operativa en algunas zonas del suroeste de China y se ganó el apoyo de la población desarrollando tareas caritativas o humanitarias como el reparto de comida a los campesinos ${ }^{26}$.

Hacia el fin de la dinastía Han, el grueso de la población percibía el taoísmo como un movimiento organizado comparable al budismo y, a pesar de que algunos consideraban que era una doctrina falseada que había promovido la subversión, lo cierto es que sus sistemas jerárquicos y sus argumentos de autoridad se encontraban ya diseminados por buena parte del territorio chino. Tanto es así que aquellas facciones que supieron limitar su actividad política contra el gobierno sin perder los principios de compromiso social que desarrollaron en el ambiente de revuelta en el que surgieron, han sobrevivido hasta nuestros días. Un ejemplo de esto es la figura religiosa del Maestro Celestial (Tiānshī 天師) que aún pervive en Taiwán ${ }^{27}$.

\section{Taiping Jing: Fuente para la institucionalización del taoísmo religioso}

Como ya he mostrado, muchas de las claves del éxito de este texto se encuentran en lo apropiado del mensaje mesiánico al momento histórico de finales de los Han, que debido a las malas cosechas, las hambrunas y el caos en la corte, era percibido por la sociedad como una situación de caos generalizado. En este contexto, el TPJ se presenta con este nombre-Taiping Jing 太平經 «Escritos sobre la Gran Paz»otorgándose a sí mismo la categoría de jīng 經 y la autoridad social, política y moral que esto implicaba.

El concepto de Gran Paz Tàipíng que da nombre a este clásico (jīng) es muy utilizado en el periodo histórico de finales de los Han hasta la fundación de la dinastía Tang, momento en el que el imperio vuelve a unificarse en paz. Esta popularidad se debe en parte a la capacidad del término para remitir a la idea de un reino de paz y equilibrio unificado bajo un emperador que gobierna a través de la virtud (dé 德) ${ }^{28}$. La visión de este reino ya estaba presente en el ideario chino: para Zhuang Zi se trataba de un reino acorde al orden de la naturaleza, Xun Zi 荀況 (murió en torno al 238 a. C.) habló de una sociedad en la que cada cual ocupa el puesto que le corresponde y lleva a cabo sus obligaciones de acuerdo a sus capacidades y en el Liji 禮記, la Gran Paz es aquello que se obtiene cuando el gobernante comprende la naturaleza de los ritos y la música y gobierna mediante la no-acción (wúwéi 無為). Todas estas visiones coinciden en la necesidad de un emperador que sirva de vehículo a la virtud, lo que en comentarios a la obra de Confucio se ha denominado un Rey Verdadero, es decir, aquel que ha obtenido el Mandato del $\mathrm{Cielo}^{29}$.

La dinastía Han vinculó su forma de gobierno al sistema confuciano de letrados $r u ́$, quienes se otorgaban el papel de maestros o letrados con una categoría social similar a la de los nobles de los reinos de Zhou (1046-256 a. C.) y Lu (1042-249 a. C.) y que tradicionalmente debían aconsejar al emperador para actuar acorde al canon confuciano y así obtener un gobierno ideal como ya lo consiguieron otros

Demiéville 1986, 808-820.

Hendrischke 2000, 134s.

Seidel Dic. 1984, 161-174.

Kaltenmark 1979, 19-45. 
emperadores en el pasado. Con el declive de la dinastía Han, los letrados confucianos quedaron desacreditados. La incapacidad para solucionar el sufrimiento de la sociedad les hizo perder credibilidad como ayudantes del emperador y a éste, los desastres naturales y sociales ocurridos en respuesta a su mal gobierno le hicieron perder el mandato otorgado por el Cielo, mandato que se empezaban a adjudicar los protagonistas de las revueltas quienes, escudándose en que actuaban de acuerdo a los nuevos designios del Cielo, intentaban derrocar el sistema imperial vigente.

Estos rebeldes contrarios al sistema se autodenominaron seguidores de la escuela Huang-lao 黄老 haciendo referencia al nombre del Emperador Amarillo Huang, personaje legendario que habría gobernado a través de la no-acción (wúwéi) y sirviendo de canal para la virtud (dé) del tao ${ }^{30}$. Este movimiento, que quedó fuera de la burocracia imperial cuando los Han apostaron por un modelo confuciano basado en los textos editados por la clase rú, apoyaba su lógica en las teorías taoístas del yin-yang (yīnyáng 陰陽) y las Cinco Fases (wǔxíng 五行), basadas en la concepción cíclica del universo presente en el Zhuang Zi. Difundían textos y prácticas mánticas sobre alquimia y astrología, entre otras disciplinas, a través de distintas academias no gubernamentales y de mano de maestros, emulando la leyenda que afirma que así transmitió Lao Tse sus conocimientos al Emperador Amarillo, en una relación maestro-alumno ${ }^{31}$.

El colectivo rú y este nuevo movimiento inspirado en la cosmología taoísta legitimaban su autoridad en la posesión de conocimientos de naturaleza universal comprendidos en los textos (jīng) que formaban sus tradiciones textuales. Los rú habían legitimado la dinastía Han sobre los preceptos éticos y los ideales contenidos en las obras de Confucio y sus comentarios, tomando como modelo al Reino de Zhou y desarrollando el concepto del Mandato del Cielo ${ }^{32}$. Así, diseñaron un sistema político complejo y burocratizado en el que la autoridad moral y la validez política dependían de la cultura, entendida como los textos que formaban su canon, y la capacidad de acceder a ella. En este sistema, los rú se erigían como únicos especialistas de los clásicos y responsables por tanto de los ritos conducentes a armonizar el gobierno de los hombres con el del mundo espiritual y de los ancestros. Esta clase letrada rú y sus ideales, contrastaban con el gobierno minimalista y el valor del individualismo que Sima Qian 司馬遷 (145 ó 139 a. C.-89 a. C.) atribuyó a los seguidores del pensamiento Huang-lao del siglo II a. C., en su mayoría hombres de guerra que habían obtenido su prestigio a través de méritos militares y cuyas ideas, de carácter más esotérico, gozaron de popularidad durante la fundación de la dinastía Han hasta que el emperador Wu confirió carácter preeminente al canon de los rú y la corriente Huang-lao quedó fuera del ámbito oficial ${ }^{33}$.

La legitimidad del canon rú provenía de su vinculación con la figura de Confucio, a quien se atribuía su autoría o compilación y con el periodo legendario del reino de Zhou pero, con la caída de la dinastía Han que lo encumbró, estas fuentes de autoridad ya no eran válidas. Los maestros que habían estado durante los primeros años de la etapa Han difundiendo las prácticas taoístas del pensamiento Huang-lao surgían como posibles sustitutos de los rú en sus labores de guías del emperador y

\footnotetext{
Seidel Dic. 1984, 165, 166.

Csikszentmihalyi 2000, 53-73.

Loewe 1986 y 2005.

Lewis 1999, 339-341.
} 
se agrupaban, como ya hicieran los confucianos, en torno a autoridades textuales: en este caso el Daode Jing y el TPJ, que no sufrían descrédito puesto que se presentaban fruto de una fuente de conocimiento superior que no dependía de los modelos del pasado; constituían en cambio una expresión del aliento primordial anterior a la cosmogénesis y que el Cielo revelaba en el momento indicado ${ }^{34}$. En el caso del TPJ, para impulsar el cambio de ciclo y salvar a la sociedad del caos $^{35}$.

時人傳受邪偽久, 安能卒自改正乎哉? 遂從是常冤, 因為是連久, 天憐 之。故上皇道應元氣而下也, 子勿怪之也。(Wang Ming Bian 1960, 60) ) $^{36}$

La corrupción y el engaño azotan a nuestros contemporáneos desde hace mucho tiempo. ¿Es posible que se reformen de un día para otro? Hay tanto dolor que el propio Cielo se ha apiadado y no debiera sorprendernos que el grandísimo tao descendiera sobre nosotros junto al primordial $q i$.

A la cabeza de esta revelación se encontraban los maestros, cuyo papel en el movimiento fue clave, tanto es así que el propio $T P J$ está escrito en forma de diálogo. En él, el maestro responde a las dudas del alumno y nos presenta de este modo el mensaje revelado por el Cielo. En la sección 50 解師策書訣 «Explicación de la declaración del maestro», el maestro legitima así su papel en la búsqueda de la Gran Paz:

吾迺上鿷於天, 親見遣, 而下為帝王萬民具陳, 解億萬世諸承負之謫也; 吾 著，我也，我著，郎天所急使神人也。(Wang Ming Bian 1960, 64) (7 $^{37}$

Marché del cielo y me aparecí aquí en persona para explicar a los emperadores, los reyes, y las diez mil personas los detalles para la redención del millón y las diez mil generaciones de los males que reciben y transmiten (Chéng fù zhī zhé 承負 之謫) [...] Soy un enviado del cielo, entre hombre y espíritu, en misión urgente.

Cuando el alumno pregunta por la procedencia de los conocimientos del maestro este responde:

然吾始學之時, 同問於師, 非一人也, 久久道成德就, 迺得上與天合意, 迺後知天所欲言, 天使太陽之精神來告吾, 使吾語; 故吾者迺以天為師。雖 喻真人, 響天不欲言, 吾不敢妄出此說。(Wang Ming Bian 1960, 70) ) $^{38}$

Cuando comencé mis estudios, también yo buscaba el consejo de mis profesores, de más de uno. Tanto mi tao como mi virtud fueron madurando a lo largo de mucho tiempo, hasta que por fin entré en sintonía con el cielo. Fue entonces, y no antes, cuando comprendí el mensaje de los cielos. Estos enviaron al espíritu vital del gran Yang (jīng shén 精神) para instruirme y hacerme hablar. El cielo es mi maestro. Gusto de enseñar, pero jamás explicaría algo contraviniendo sus deseos.

\footnotetext{
Robinet 1993, 21-24.

Espesset 2009, 1097.

Esta idea de cambio de ciclo impulsada por una revelación se sostiene en lo que parecía ser una creencia extendida en la época. Bokenkamp, en su traducción del Xiang'er (1997) -texto que data del mismo periodo que el TPJ-también utiliza esta retórica mileniarista, con la diferencia de que, en su opinión, el Xiang'er estaba dirigido a la gente (Bokenkamp 1997, 37), mientras que el TPJ se considera un texto dirigido a las élites.

36 Hendrischke 2007, 145.

37 Ibíd., 155.

38 Ibíd., 160.
} 
Con estas frases, el maestro se erigía como la cabeza del proceso de la revelación y legitimaba su papel como interlocutor del cielo e intermediador para la redención. La lógica que apoyó el aumento de prestigio de los maestros en este proceso de «autodivinización» [self-divinization] ${ }^{39}$ que explica el TPJ, y por la que el maestro se nombra discípulo del Cielo (yītiān wéi shī 以天為師), podría considerarse una consecuencia histórica de la lógica china de deificación de la figura de filósofos y maestros como Lao Tse ${ }^{40}$. Puett explica la creciente importancia del concepto de «autodivinización» en términos históricos ${ }^{41}$, en su opinión -que se basa mayoritariamente en su lectura de otro texto mileniarista de la época: el Xiang 'er 想二 (comúnmente traducido como "pensando en ti») $)^{42}$ - la popularización de estas prácticas conducentes a la «autodivinización» está estrechamente relacionada con la instauración de un modelo cosmológico contrario por parte del emperador ${ }^{43}$. De acuerdo a la interpretación de este autor, los movimientos mesiánicos de la época Han se habrían servido del poder emancipatorio de una cosmología heterodoxa que permitía, a través del auto-cultivo, alcanzar lo que en el Xiang'er se denomina el Uno. Así, al poder alcanzar el mensaje revelado directamente de mano del Cielo a través del auto-cultivo y sin necesidad de mediación burocrática, los maestros obtenían un importante grado de independencia del poder imperial y la capacidad de instaurar un orden jerárquico alternativo.

Una vez expuesta la importancia de los textos para legitimar de un modo u otro los cambios dinásticos a lo largo de la historia de China, cabe destacar que lo novedoso del TPJ es que modificó la cosmología taoísta del yin-yang y las Cinco Fases para servir a sus objetivos ${ }^{44}$. Este texto se presentó como revelación y generó comunidad organizando a las personas como entes individuales capaces del cambio en torno a su mensaje milenarista ${ }^{45}$.

A diferencia de los confucianos, cuyo valor fundamental era el comportamiento ritual apropiado a cada situación y persona, los seguidores del Huang-lao defendían la importancia de la visión taoísta de la «vida»o «destino» (mìng 命). El qi de la «vida», y no tanto los ritos, era lo que en su opinión estaba presente en todas las capas sociales, cohesionándolas y haciendo fluir los bienes y la información entre ellas. El comportamiento moral no era el que se ceñía a la piedad filial confuciana (xiào 孝) sino aquel que ayudaba a propagar y preservar la vida y sobre este pensamiento se debían construir las normas de conducta y también la ley, como indica la sección 54 del TPJ 樂生得天心法 «Cómo disfrutar dando vida hace ganar el favor del cielo»:

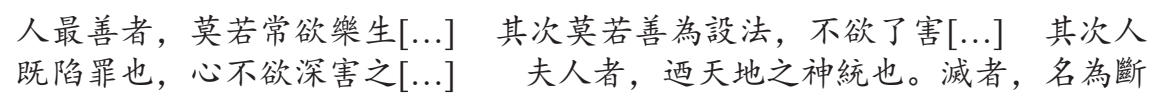

\footnotetext{
Este término se desarrolla en profundidad en la obra de Puett (2002) y es compartido también por Espesset.

Espesset 2009, 1093.

Puett 2004, 19-23.

42 Hendrischke $(2007,26-29)$ también hace referencia a la estrecha relación que existe entre estos dos escritos, sus objetivos y los métodos que proponen. Es importante destacar que ambos textos parecen compartir la noción de ortodoxia y la necesidad de un maestro o guía que ayude a discernir entre la verdadera y la falsa doctrina. Bokenkamp (1997) suscribe la tesis de Hendrischke a este respecto. Para un estudio detallado de las prácticas de los Maestros Celestiales recogidas en el Xiang'er ver: Bokenkamp Dic. 1993.

43 Para mayor información sobre estas prácticas ver: Csikszentmihalyi 2000.

44 Hendrischke 2000, 148.

45 Del mismo modo que, de acuerdo con la ya mencionada lectura que Puett hace del Xiang'er, ocurre con otros movimientos taoístas de carácter milenario en esta misma época.
} 
絕天地神統, 有可傷敗於天地之體, 其為害甚深, 後亦天滅鞄人世類 也。(Wang Ming Bian 1960, 80) ${ }^{46}$

Lo más adecuado en los actos de los hombres y el gobierno de los reyes es siempre el deseo de dar vida [...] Lo siguiente es la diligencia en la legislación, la renuncia a agraviar a terceros por gusto o interés. A continuación está el afán por evitar que quien se vio involucrado en un crimen sufra graves daños [...] el hombre existe en tanto que el cielo y la tierra vierten en él su espíritu. Destruir conlleva la ruptura de esa unión, y esto a su vez daña la materia (tí 體) del cielo y la tierra. Esto es algo verdaderamente grave, y [podría] el cielo acabar con la vida de toda una generación en respuesta.

Se exponían así las bases para una nueva moral con la vida como elemento central, lo cual ampliaba las responsabilidades morales a todos los individuos poseedores de vida. Los deberes morales adquirían así carácter personal, ya no era el Cielo quien dispensara las leyes de lo correcto a través del Emperador, ahora el Cielo controlaba la moral de los comportamientos individuales a través de un sistema de retribución:

然活人名為自活，殺人名為自殺。天愛子可為已得增等於天，司命易子籍 矣。(Wang Ming Bian 1960, $34^{47}$

Dar vida al prójimo es darse vida a uno mismo. Es posible que la preocupación del Cielo por ti haya elevado tu deuda con Él. Así, el Supervisor del Destino (deidad que habita el cuerpo y que supervisa el comportamiento moral de la persona) modificará el informe de tu vida.

Esta creencia común de la época de que el Cielo y las deidades eran los encargados de repartir justicia y que la posibilidad de ascender al Cielo de mano de los inmortales dependía del valor moral de los actos en vida ${ }^{48}$ obligaba al TPJ a definir el concepto de «mal» y a validarlo sobre los términos de la retribución.

凡天下事何者是也? 何者非也? 試而即應，事有成功，其有結疾病者解 除, 悉是也。試其事而不應, 行之無成功, 其有結疾者不解除，悉非，非 一人也。善哉, 子之言真是也。(Wang Ming Bian 1960, 71) (9 $^{4}$

¿Entre los actos de los que son testigos los cielos, cuáles son los buenos y cuáles son los malos?

Prueba que un acto es apropiado: (podrás entonces decir que) es meritorio. Es por esto que todo aquello que cura (jiěchú 解除, su otro significado es «exorcizar») $)^{50}$ la enfermedad del afligido es bueno. Una acción cuya conveniencia no puedes probar equivale a una conducta no meritoria: aquello que no cura la enfermedad es malo. Esto no sólo es aplicable al gobernante.

De acuerdo a este fragmento, lo bueno y lo malo adquirirían su nivel moral en base a su relación con la vida y el efecto retributivo que tuvieran sobre ella. De este

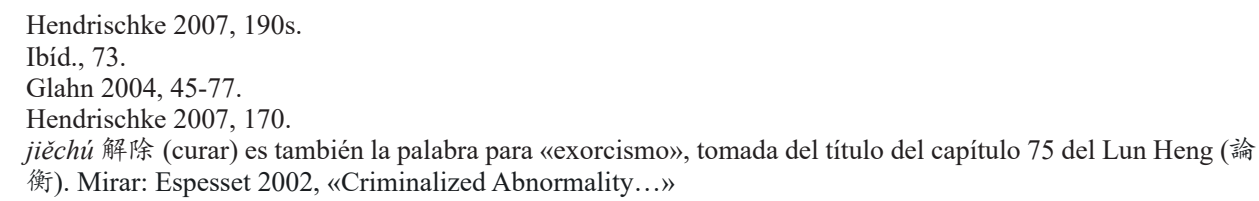


modo todo aquello que afligiese o generase enfermedad sería malo y toda acción que condujese a la liberación de esta situación sería bueno y así lo retribuiría el Cielo.

El TPJ sistematizó los procesos del «mal» en los términos de males heredados (chéng fù 承真) y de recepción y transmisión de calamidades (chéng fù zhī zhé 承 負之謫).

本道常正，不邪偽欺人。人但座先人君王人師父教化小小失正，失正言， 失自飬之正道，遂相效學，後生者日益劇，其故為此。[…] 故災變萬種與 起 [...] 天下悉邪，不能自知。(Wang Ming Bian 1960, 59s.) ${ }^{51}$

Todo lo que ha sido enseñado era en origen fiable y correcto, sin ápice de falsedad o engaño, pero lo que ancestrales reyes, maestros y padres enseñaron hizo al hombre perder parte de aquella corrección. Lo hizo olvidar la manera correcta de expresarse, de la misma manera que lo hizo olvidar la manera correcta de nutrir su propio ser. Puesto que el hombre aprende imitando, el problema se agravó con cada generación [...] De ahí los desastres naturales, las desgracias [...] El hombre está equivocado, y no puede por sí mismo discernir qué es lo correcto.

El «mal» serían por lo tanto todas aquellas prácticas individuales o colectivas que se habrían ido malversando durante el proceso de transmisión y que se habrían acumulado, derivando en desastres y epidemias que atentaban contra la vida ${ }^{52}$. La sociedad «enferma» o «afligida» de los Han sería el resultado de la pérdida generalizada de valores en todas las escalas sociales ${ }^{53}$. Con el paso de las generaciones el ser humano habría perdido la capacidad de discernir la carga moral contenida en sus actos cotidianos al alejarse cada vez más de las costumbres que se practicaban en tiempos del Reino de la Gran $\mathrm{Paz}^{54}$. Para el TPJ por tanto, el deterioro social sería síntoma de deterioro moral.

Ante la acuciante gravedad del deterioro social en la época Han, el mensaje salvífico del TPJ adquirió carácter de urgencia. La incapacidad del hombre y del sistema político de los ru para poner fin al ciclo de transmisión del mal justificaban la revelación del TPJ, la necesidad de las prácticas que difundía y la vuelta a la figura del maestro.

Teniendo en cuenta que el origen del caos se encontraba en la perversión gradual de prácticas individuales cotidianas, su solución también debería pasar por la redención del individuo. Siguiendo esta lógica y como muestra la siguiente cita, el método para reequilibrar la sociedad y redimirse de estas malas acciones que proponía el TPJ era una vuelta al origen, a lo más básico dentro de cada individuo; cada uno habría de recuperar la capacidad para nutrir su qì y armonizarse con el Tao para, posterior-

51 Hendrischke 2007, 145.

52 Hendrischke 2000, 151.

En la lectura de Puett (2004) estas prácticas implicarían también la pérdida de pureza del mensaje del Cielo a causa de su transmisión histórica entre los hombres.

53 El Xiang'er apunta en una dirección similar al TPJ en este respecto. Además, en este texto, seguir los mandatos del Tao implica necesariamente conocerlo de forma autónoma, al margen de la tradición, lo que otorga a los maestros independencia de la ortodoxia imperial vigente (Puett 2004, 20).

54 El estudio de textos expiatorios y oraciones de la dinastía Han que lleva a cabo Donald Harper (2004) apoya el argumento de que en esta época existía la percepción de una necesidad de redención. Sin embargo, el autor utiliza el concepto de «deuda» zhài 債 para acentuar que el caos se debe a una falta de rigor de los hombres hacia sus obligaciones rituales con el Cielo, sin destacar expresamente la carga moral de estas obligaciones en la forma en la que lo hacen el TPJ o el Xiang'er. 
mente, ayudar a otros en esta labor 然, 夫人能深自飬, 迺能飬人。夫人能深自 愛，迺能愛人 (Wang Ming Bian 1960, 56) ${ }^{55}$ «Un hombre sólo puede hacer crecer a otro una vez él mismo ha crecido. Un hombre puede valorar a otro únicamente después de haber encontrado su propio valor». Los métodos para sanar el microcosmos personal y así reflejar esta rearmonización en el macrocosmos social comprendían desde técnicas de respiración para guardar el Uno (shǒu ȳ̄ 守一) y nutrir el qì hasta la confesión de las malas acciones cometidas para frenar su transmisión y eventualmente, curarse de los daños que estas acciones estuvieran produciendo al confesor.

La práctica de guardar el Uno se consideraba por sus practicantes la esencia de la meditación taoísta y el secreto para la longevidad. Consiste en practicar la concentración y la consciencia en el origen y la unidad de los componentes que constituyen a la persona: aliento, esencia y espíritu; como indica la frase 《思守一» «Mantente guardando el Uno en tus pensamientos» (Wang Ming Bian 1960, 60) ${ }^{56}$. La mayoría de las prácticas concretas que plantea el texto otorgan gran importancia a la visualización del cuerpo y la víscera. De acuerdo con estas prácticas, cada víscera sería la morada de un espíritu y la representación interna de los cinco agentes. Como indica el texto, la enfermedad de la víscera sería la ausencia de espíritu, lo que provocaría síntomas visibles en los órganos externos. 《神去則氣絕，氣亡則神去》 (Wang Ming Bian 1960, 96) ${ }^{57}$ «De marcharse los espíritus el flujo del qi se pararía. De perderse el $q i$, los espíritus se marcharían ${ }^{58} \gg$. Los espíritus de las vísceras habitan lugares en calma por lo que sería importante aprender a cuidar los órganos para que el espíritu no se marche o para hacerle volver. Para esto se proponía la meditación, el poder del pensamiento haría que al concentrar la consciencia en la visualización del órgano y el espíritu, estos se mantuviesen juntos en su sitio; en unidad. Estos ejercicios recreaban el doble movimiento que surge del Uno y que va de la división a la unidad simbolizando el origen y el fin del universo ${ }^{59}$. Estas prácticas pueden entenderse como la recreación individual dentro de cada uno de la unidad y equilibrio que falta en la sociedad. Otra relación entre lo que ocurre en el cuerpo y la situación social puede verse en la creencia de que la enfermedad no sería sólo la ausencia del espíritu ante un agente externo que perturba nuestra víscera, un comportamiento no ético también haría marcharse al espíritu de la víscera ${ }^{60}$.

El TPJ continua asegurando que los hombres serían responsables del caos por haber actuado contra los deseos del Cielo

今人實惡, 不合天心, 故天不具出其良藥方也。反日使鬼神精物行考, 若 擊其無狀之人，故病者不絕，死者眾多也。(Wang Ming Bian 1960, 138) ${ }^{61}$

Hay hoy en los hombres auténtica maldad. No satisfacen los deseos del Cielo. Es por esto que el Cielo no les bendice con todas sus poderosas sustancias medicinales, sino que los castiga con demonios, espíritus y demás entes que buscan y atormentan a quienes obran mal. Es por esto que las enfermedades nunca terminan y la muerte tiene mil formas.

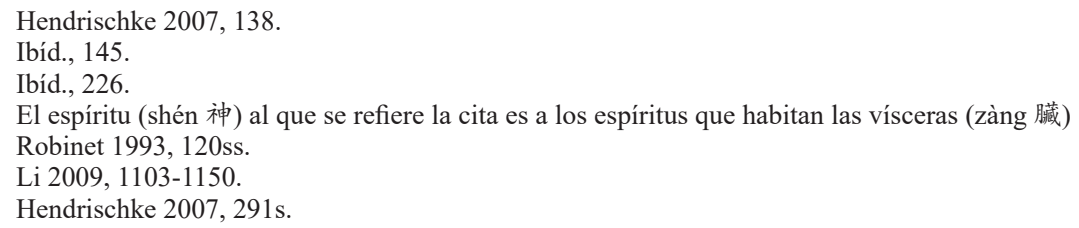


Esto es especialmente interesante para justificar la necesidad de confesión y redención, ya no sólo para frenar el ciclo de transmisión del mal, sino también para velar por nuestro propio bienestar ahora y en la otra vida. De acuerdo con el TPJ, las soluciones para los males comunes de la humanidad estarían en nuestras acciones individuales.

\begin{abstract}
凡人悉愚，不為身計，皆以邪偽之文。無故自欺殆，冤哉！反得天重謫, 而生承負之大責，故天使其 $[. .$.$] 各守真實，保其一旦夕力行之，令人人各$ 有益其身，無肯復自欺殆者也。(Wang Ming Bian 1960, 67) ${ }^{62}$

Ingenuos los que en vez de pensar por sí mismos emplean, en su ingenuidad, falaces embustes para engañar. ¡Lamentable! Quedan, a cambio, señalados por el cielo. Generan un cúmulo de maldad que se transmite y hereda [...] Que cada hombre preserve lo que es auténtico y esencial y salvaguarde el uno. Que se consagre día y noche a ello y verá que es fructífero y no volverá a engañar.
\end{abstract}

Con esta frase el maestro defiendía la efectividad de la confesión en la prevención y cura de los males mientras enfatizaba la importancia de lo verdadero y lo esencial. La compilación de los mensajes considerados verdaderos o esenciales sería por tanto clave para llevar a cabo el proceso de redención a gran escala. En el TPJ el maestro hace un llamamiento a la recolección de esta sabiduría que, aunque escrita por el hombre a lo largo de la historia, bebería de la sabiduría del Cielo y una vez reunida y clasificada por los caballeros meritorios e iluminados ayudaría a acercar a los hombres al mensaje original del Cielo y a difundirlo.

然, 所言拘校上古中古下古道書者, 假令眾賢共讀視古今諸道文也 $[. .$.$] 書$ 而記之, 聚於一間處 [...] 其要文字而編之, 即已究竟, 深知古今天地人萬 物之精意矣。因以為文, 成天經矣。(Wang Ming Bian 1960, 84) ${ }^{63}$

Esta es la razón de recopilar y revisar los escritos sobre el dao de toda la antigüedad. Que puedan todos los hombres de virtud juntos recitar y contemplar el conjunto de los textos [...] Que (lo que sea valioso) se ponga y se conserve por escrito reunido en un único lugar. Que (los hombres de virtud) los editen de acuerdo a ciertas palabras clave (yào wén zì 要文字). De concluir, habremos adquirido un profundo conocimiento de lo que forma la esencia del cielo y de la tierra, del hombre y de los diez mil seres del pasado y del presente. De estos escritos nacen los clásicos del cielo (tiān jīng 天經)

En estas palabras del maestro podemos inferir un llamamiento a la cohesión, a la compilación de estos saberes de origen taoísta y en definitiva, a la creación de un canon textual. El maestro apostaría en este fragmento por la unidad de todas las escuelas para garantizar el éxito de la labor mesiánica y sentaría así las bases para la unión del taoísmo:

古今天文聖書賢人辭已備足, 但愁其集居, 各長於一事耳。今案用一家法

也，不能悉除天地之災變，故使流災不絕。(Wang Ming Bian 1960, 86) ${ }^{64}$ 
Antiguos y nuevos textos celestiales, escritos cargados de sabiduría, expresiones de virtud. Todos son completos por sí mismos. Sin embargo, al estar todos juntos nos damos cuenta de que cada uno es apropiado para un tema. Si sigues el modelo (establecido) por una sola (escuela) no podrás combatir todas las desgracias del cielo y la tierra. Seguirán recibiéndose y transmitiéndose sin fin.

\section{Conclusión}

En este artículo he argumentado que en el mensaje del TPJ y en la organización que creció en torno a él durante la dinastía Han se encuentran algunas de las claves para comprender el impulso inicial con el que el discurso taoísta comenzó un proceso de institucionalización que resultaría en la compilación de una autoridad textual taoísta en forma de canon y finalmente, en la organización jerárquica que algunos autores contemporáneos han llamado «Iglesia Taoísta».

El argumento principal es que la revisión y apropiación de la moral que llevaron a cabo los maestros en torno al concepto de vida, generó una identidad y un discurso independiente del que conformaba la ortodoxia vigente en la dinastía Han, lo que tuvo una repercusión política directa. El contexto socio-político de esta época dejó de estar regido por un modelo en el que la tradición confuciana rú y la filosofía taoísta coexistían a distintos niveles. Este nuevo grupo, que sitúa la figura del maestro en contacto directo con el Cielo, compartía una misma visión de la cosmológica taoísta y se volvió crítico con el poder imperial. Como he expuesto, su popularización fue consecuencia directa del contexto social y de haberse servido de la legitimidad que la categoría jing otorgaba al texto para dotar de autoridad a su discurso vinculándolo con una fuente de conocimiento que, a diferencia de la de los clásicos confucianos, era de carácter trascendental: la revelación. De este modo, las academias no gubernamentales adheridas al pensamiento Huang-lao y sus maestros, conocedores de los procesos naturales que daban cuenta del fin de ciclo y de los métodos que el TPJ recetaba para alcanzar el Reino de la Gran Paz, ganaron popularidad en detrimento de los ideales confucianos rú. La organización de estos maestros como garantes de la armonía y la popularización de los conceptos del $T P J$ resultaron en movimientos rebeldes que, con promesas mesiánicas, contribuyeron a la difusión de ideas religiosas heterodoxas y sus instituciones a todos los niveles de la sociedad.

\section{Bibliografía}

T. H. Barret, «Religious change under eastern Han and its successors: some current perspectives and problems» (ed.) M. Loewe, China's Early Empires a Re-appraisal (2010) 430448. Cambridge, New York: Cambridge University Press.

S. R. Bokenkamp, Early Daoist Scriptures. Berkeley, Los Angeles, London, 1997.

- «Traces of Early Celestial Master Physiological Practice in the Xiang'er Commentary», Taoist Resources 4.2 (Dic. 1993) 37-51.

R. F. Campany, Ge Hong's Tradition of Divine Transcendents, Berkeley, Los Angeles, London, 2002.

M. Csikszentmihalyi, «Han Cosmology and Mantic Practices», (ed.) L. Kohn, HdO Daoism Handbook (2000) 53-73, Leiden, Boston, Köln. 
P. Demiéville, «Philosophy and Religion from Han to Sui», (eds.) M. Loewe y D. Twitchett, The Cambridge History of China (1986) 808-820, Cambridge.

G. Espesset, «Editing and Translating the Taiping Jing and the Great Peace Textual Corpus», Journal of Chinese Studies, 48 (2008) 469-486, http://www.cuhk.edu.hk/ics/journal/arti cles/v48p469.pdf [acceso: 31.05.2016].

— «Latter Han Religious Mass Movements», (eds.) M. Kalinowski y L. John, HdO Early Chinese Religion Part One: Shang through Han (1250 BC-229 AD), Leiden, Boston, 2009.

— «Revelation Between Orality and Writing in Early Imperial China: The Epistemology of the Taiping jing», Bulletin of the Museum of Far Eastern Antiquities (Östasiatiska Museet) 74 (2002) 66-100, https://halshs.archives-ouvertes.fr/halshs-00669666/docu ment [acceso: 31.05.2016].

— «Criminalized Abnormality, Moral Etiology, and Redemptive Suffering in the Secondary Strata of the Taiping jing» Asia Major 15 (2) (2002) 1-50, https://halshs.archives-ouver tes.fr/halshs-00669076/document [acceso: 31.05.2016].

R. V. Glahn, The Sinister Way, The Divine and the Demonic in Chinese Religious Culture, Berkeley, Los Angeles, London, 2004.

M. Granet, «Remarques sur le Taoïsme Ancien» Asia Major 1 (2) (1925) 146-151, http:// www2.ihp.sinica.edu.tw/file/1151hhkDtrw.pdf [acceso: 25.03.2017].

D. Harper, «Contracts with the Spirit World in Han Common Religion: The Xuning Prayer and Sacrifice Documents of A.D. 79» Cahiers d'Extrême-Asie vol. 14 (2004) 227267. DOI: 10.3406/asie.2004.1209; http://www.persee.fr/doc/asie_0766-1177_2004_ num_14_1_1209 [acceso: 25.03.2017].

B. Hendrischke, «Early Daoist Movements» (ed.) L. Kohn HdO Daoism Handbook (2000) 134-164, Leiden, Boston, Köln.

— «The concept of inherited evil in the Taiping Jing», East Asian History no.2 , (Dic.1991) 1-30, http://www.eastasianhistory.org/sites/default/files/article-content/02/EAH02_01. pdf [acceso 31.05.2016].

- The Scripture on Great Peace: The Taiping Jing and the Beginnings of Daoism, Berkeley, Los Angeles, California, London, 2007.

M. Kaltenmark, «The Ideology of the T'ai-P'ing Ching» (eds.) A. Seidel y H. Welch, Facets of Taoism New Haven, London, 1979, 19-45.

H. S. Levy, «Yellow Turban Religion and Rebellion at the End of Han», Journal of American Oriental Society Vol. 76, no 4, (Oct.-Dic. 1956), 214-227. DOI: 10.2307/596148; http:// www.jstor.org/stable/596148 [acceso 31.05.2016].

M. E. Lewis, Writing and Authority in Early China, Nueva York, 1999.

J. Li, «They Shall Expel Demons: Etiology, the Medical Canon and the Transformation of Medical Techniques Before the Tang» (eds.) J. Lagerwey y M. Kalinowski, HdO Early Chinese Religion, Part One: Shang thorugh Han (1250 BC-220 AD), 1103-1150, Leiden, Boston, 2009.

S. N. C. Lieu, «The 'Romanitas' of Xi'an inscription» (eds.) Li Tang and D. W. Winkler, From the Oxus river to the Chinese shores : studies on East Syriac Christianity in China and Central Asia, Zurich, 2013123-140,.

M. Loewe, Everyday Life in Early Imperial China, Indianapolis, Cambridge, 2005.

- Faith, Myth and Reason in Han China. Indianapolis, 2005.

— «The Former Han Dinasty» (eds.) D. Twitchett y M. Loewe, The Cambridge History of China (1986) Vol.1 The Ch'in and Han Empires, 221 B.C - A. D. 220, 103-222, Cambridge. 
B. J. Mansvelt Beck, «The Date of the Taiping Jing» T'oung Pao 2nd Series, Vol. 66, Livr. 4/5 (1980) 149-182, http://www.jstor.org/stable/4528198 [acceso: 31.05.2016].

T. Masaaki, «Confessions of sins and awareness of self in the Taiping Jing» (eds.) L. Kohn y H. D. Roth, Daoist Identity: History, Lineage, and Ritual (2002) 39-57, Honolulu.

M. Nylan, The Five «Confucian» Classics, New Haven, London: 2001.

N. Ofuchi, «The Formation of the Taoist Canon» (ed.) H. W. Seidel, Facets of Taoism: Essays in Chinese Religion (1979) 253-267, New Haven, London.

B. Penny, Daoism in History, New York, 2006.

M. Puett, To Become a God: Cosmology, Sacrifice, and Self-Divinization in Early China. Cambridge: Harvard University Asia Center, 2002.

- «Forming Spirits for the Way: The Cosmology of the Xiang'er Commentary to the Laozi», Journal of Chinese Religions Vol. 32 (2004) 1-27. DOI: 10.1179/073776904804760020; http://scholar.harvard.edu/puett/publications/\%E2\%80\%9Cforming-spirits-way-cosmo logy-xiang\%E2\%80\%99er-commentary-laozi\%E2\%80\%9D [acceso: 18.03.2017].

I. Robinet, Taoist Meditation. New York, 1993.

A. Seidel, «Taoist Messianism», Numen: International Review for the History of Religions Vol.31, fasc.2 (Dic. 1984) 161-174. DOI: 10.2307/3269952; http://www.jstor.org/sta ble/3269952 [acceso: 31.05.2016].

— «Sacred Scriptures. Chronicle of Taoist Studies in the West 1950-1990», Cahiers d'Extrême-Asie Vol. 5, (1989) 223-347. DOI: 10.3406/asie; http:/www.persee.fr/doc/ asie_0766-1177_1989_num_5_1_950 [acceso: 31.05.2016].

N. Sivin, (1978). «Ōn the Word 'Taoist' as a Source of Perplexity. With Special Reference to the Relations of Science and Religion in Traditional China» Chicago Journals, History of Religions Vol.17, No.3/4 (feb.-Mayo 1978) 303-330. DOI: 10.1086/462796; http://www. journals.uchicago.edu/doi/abs/10.1086/462796 [acceso: 31.05.2016].

R. Stein, «Remarques sur les Mouvements Politico-religieux au II Siècle ap. J.-C.» T'oung Pao 2nd Series, Vol. 50, Livr 1/3 (1963) 1-78, http://www.jstor.org/stable/4527541 [acceso: 25.03.2017].

R. Sterckx, «Religious Practices in Qin and Han» (eds.) M. Loewe y M. Nylan China 's Early Empires a Re-appraisal (2010) 415-430, Cambridge, New York.

C. Wang, «The revelation and classification of Daoist scriptures» (eds.) J. Lagerwey y L. Pengzhi, HdO Early Chinese Religion, Part two: The Period of Division (220-589 AD) (2010) 775-888, Leiden, Boston.

Wang Ming Bian 王明编 (ed.) Taiping Jing Hejiao yibai qishi juan 太平經合校一百七十卷 [170 rollos sobre las escuelas de los Escritos de la Gran Paz], Pekín, 1960.

Yang Jilin 杨寄林 (trad.), Taiping Jing Jin Zhu Jinyi V.1, V.2 太平经今注今译 (上, 下) [Notas y traducciones actuales de los Escritos de la Gran Paz Vol. 1 y 2] (trad. mandarín estándar), Hebei, 2002. 